\title{
Analytical, numerical and experimental studies for SERB TEL-150 new romanian seismic dampers used in foundation buildings damping system
}

\author{
Ionescu Adriana ${ }^{1, a}$ \\ ${ }^{1}$ University of Craiova, Faculty of Mechanics, Romania \\ adita_i@yahoo.com
}

Keywords: Damper, Ansys, Bouc-Wen model, earthquake security, F.E.M., civil engineering.

\begin{abstract}
This paper presents analytical, numerical and experimental studies of SERB TEL-150 new Romanian devices for dissipation of seismic energy for buildings affected by Romanian Vrancea earthquakes. These devices were invented to be positioned at the foundation of buildings and were tested in static cases. The purpose of these studies is to determine the analytical model of the special shape hysteresis of these new devices which is necessary to obtain the mathematical equation for these hysteresis curves. The experimental and the numerical analysis of SERB TEL150 were performed in order to determine the experimental and the numerical hysteresis curves which are to be modeled with a modified Bouc-Wen model. These devices were invented by PhD.eng. Viorel Serban (CITON - Center for Technology and Engineering for Nuclear Projects) and they were used for equipping NAVROM building in Galati, Romania.
\end{abstract}

\section{Introduction}

At the present time the buildings constructors use frequently viscous dampers made by Taylor devices company for dissipating the seismic energy and protecting the buildings during earthquakes. An efficient method for protecting the building during earthquakes is by using seismic dampers which can be positioned in the foundation in paralel with the isolation systems. The most common choice is structural passive control systems which have been developed in the past years and they include seismic isolation systems and energy dissipation systems.

The Romanian earthquakes have some particularities, and one of them is the velocity of the ground during earthquake, which is smaller $(0,3 \mathrm{~m} / \mathrm{s})$ then in other countries and seismic zones. Because Taylor viscous dampers damping forces are depending on the velocity, we choose to analyse a different type of damper which is not depending on velocity but on displacements.

This paper analyze a type of damper SERB TEL-150 invented for the Romanian earthquakes conditions which is a friction damper. Because this damper was analized by only a few romanian researchers, we have done experimental studies in order to obtain the experimental hysteresis curve.

In order to extend the experimental study it is necessary to performe F.E.M. analysis for comparing the numerical hysteresis with the experimental hysteresis curves.

Bouc-Wen model permits the analitical modeling of SERB TEL-150 hysteresis curve, in order to be used in programs software which simulate the behavior of the buildings equipped with these type of dampers during earthquake. One of them is GenEcAm software [4] made by the author.

\section{Numerical studies}

In this section we present the F.E.M. analysis of SERB damping device using Ansys program.

The components of this damper were modeled in Ansys software using 3d finite elements and contact friction finite elements. The load case for this $3 \mathrm{~d}$ FEM model is the axial force, which is used for elongating then compressing the damper in the same cycle.

In order to obtain the hysteresis curve we have focused on axial displacements of the central part and the damping force. 

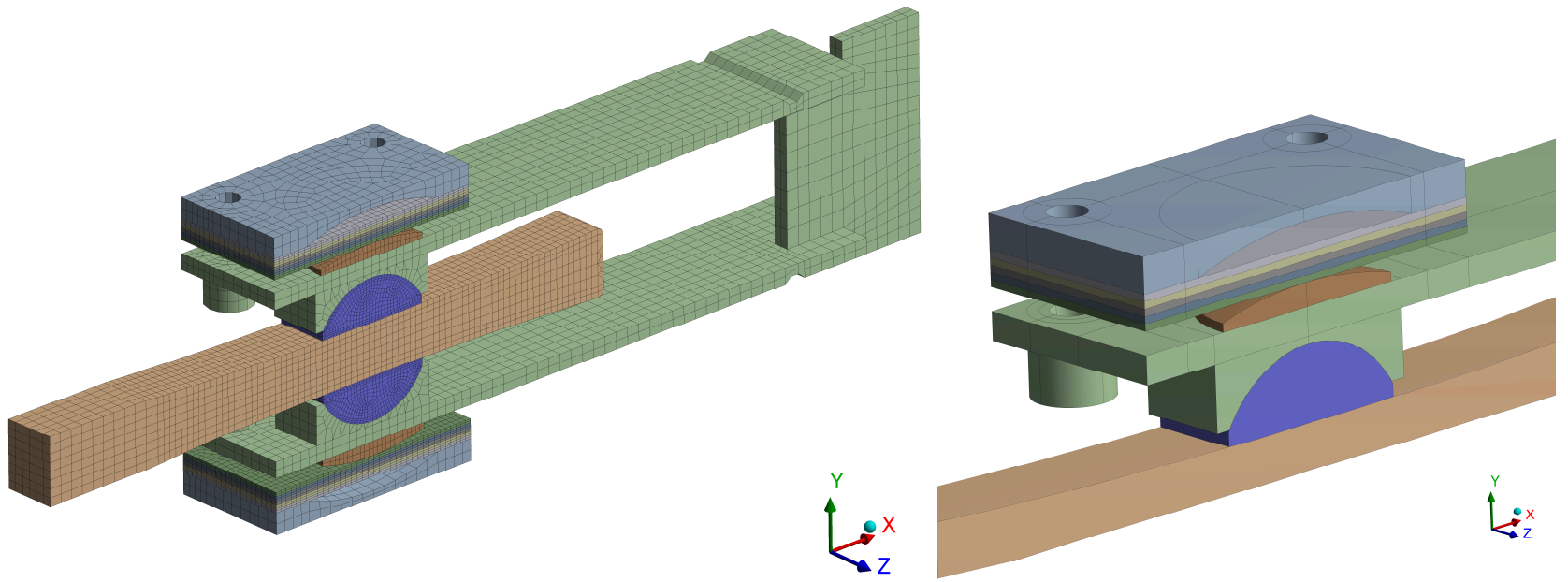

Fig. 1 Mesh model of SERB damper (sectioned and detailed)

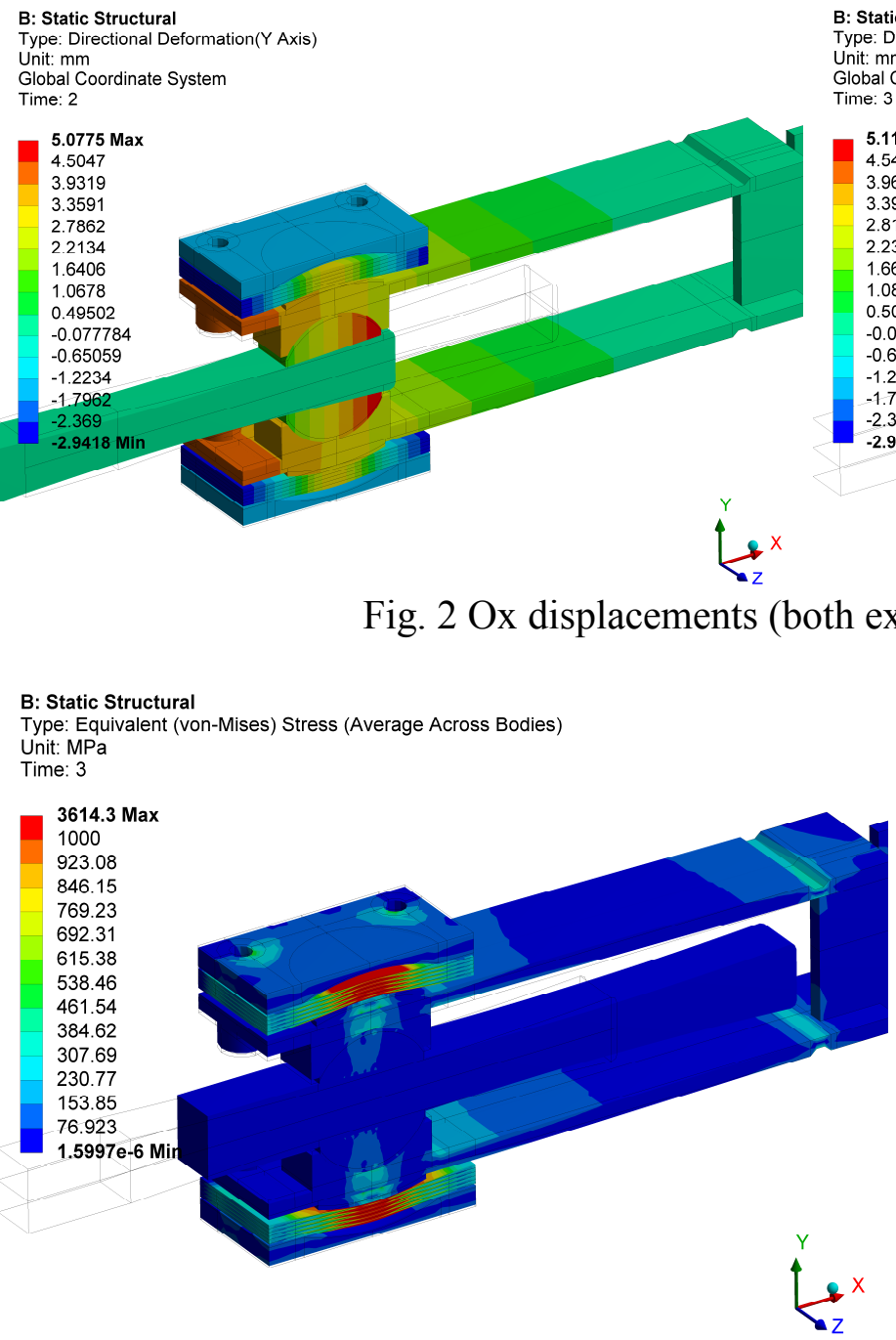

Fig. 3 Von Mises stresses (extreme position) [MPa]

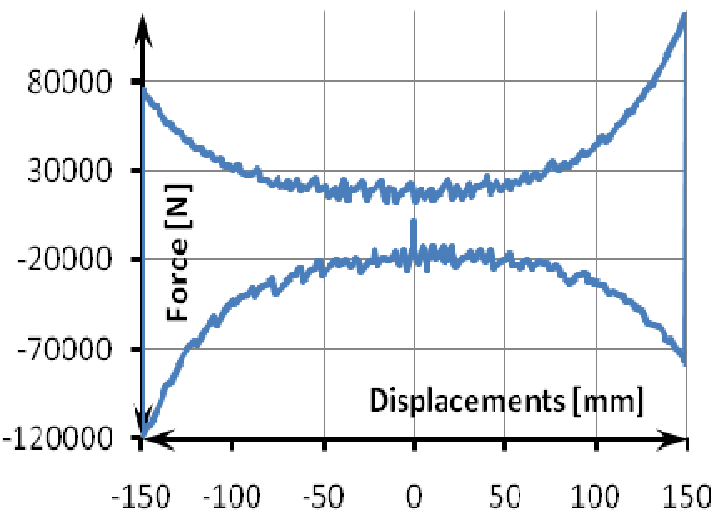

Fig. 4 Numerical hysteresis curve

For the metallic friction parts of the dampers we have used special steel features. The friction between parts was simulated using contact elements surface to surface with friction coefficient $\mu=0.3$ for friction without lubrification.

With the data obtained with Ansys program we have determined the hysteresis curve of SERB TEL-150 damper which is presented in Fig. 4. The curve has a special butterfly shape which is very useful in the building foundation damping system. 


\section{Experimental studies}

The testing was realized at IMSAR Bucharest laboratory on a special testing machine (Fig. 5.a) which acts on the damper with cycles of compression and elongation forces in static regime.
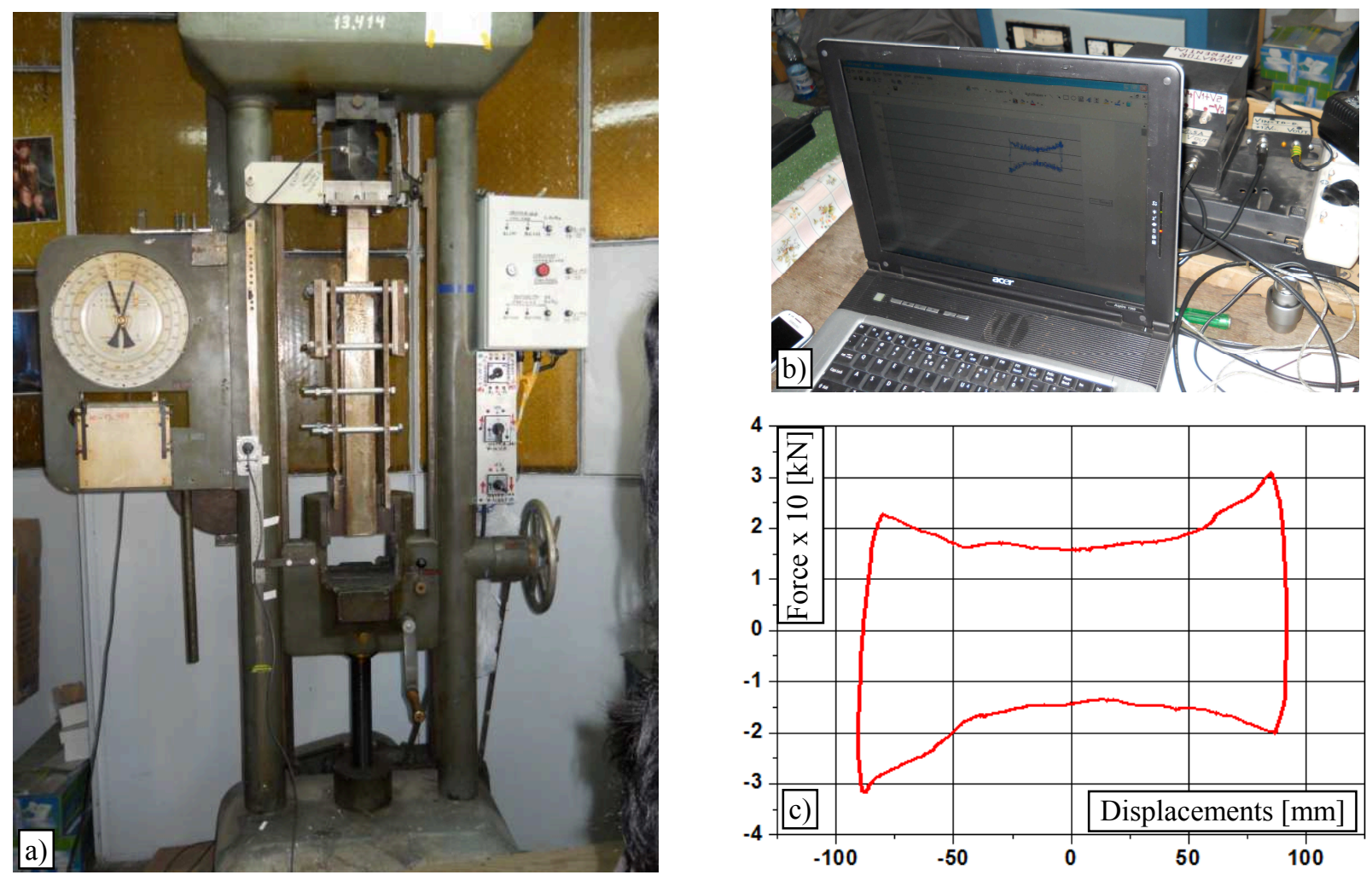

Fig. 5 Testing SERB damper at IMSAR Bucharest

The damper has metallic components in contact and the friction phenomenon during earthquakes is without lubrication. That is the reason why we have tested this damper with static compression and elongation forces, although this damper is subjected to dynamic forces during earthquakes. The results are the same in static and dynamic cases. The displacements and forces were majored with special equipements (Fig. 5.b) and it results the experimental hysteresis curve (Fig. 5.c).

This damper has the possibility to increase the friction force by acting on a system with screws and springs, resulting modified hysteresis curves.

\section{Analytical Bouc-Wen studies}

The general model of Bouc-Wen hysteresis is:

$$
\frac{d z}{A-|z|^{n}\left[\beta+\gamma \cdot \operatorname{sgn}\left(\xi^{\prime} \cdot z\right)\right]}=d \xi
$$

where: $A, \beta, \gamma, n$ are the parameters which controls the magnitude and shape of hysteresis curve, $z(\xi)$ where $z$ is the damping force and $\xi$ is the damper displacement.

For the second damper SERB TEL-150 it is recommended to use the modified Bouc-Wen model (papillon model). In this case the mathematical relation used for SERB TEL-150 hysteresis curve is:

$$
\frac{d z}{A-\beta \cdot z}=\operatorname{sgn}(\xi) d \xi
$$

For the fitting of experimental hysteresis curve of SERB TEL-150 we have found several sets of parameters $A$ and $\beta$ which satisfied the desired shape of hysteresis curve obtained by F.E.M. and experiments. In this case the theoretical hysteresis curves are presented in Fig. 6. 

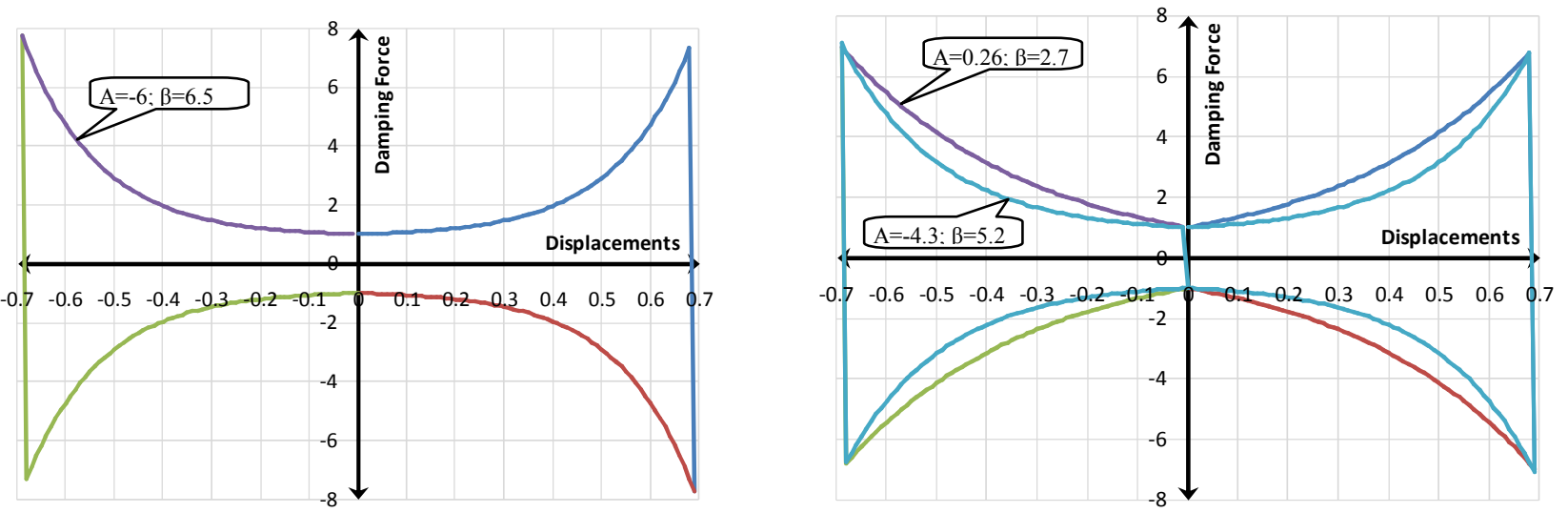

Fig. 6 Different versions of analytical hysteresis curve obtained with Bouc-Wen model for SERB TEL-150 dampers

\section{Conclusions}

The damper SERB TEL-150 it was invented by CITON eng. Viorel Serban for equipping the building at the foundation in order to work in parallel with the base isolation system during earthquakes. SERB dampers were tested by experiments by the inventor and by the author and our F.E.M. simulation extends the experimental study by using different load cases then the experiments. The numerical results are similar with the experimental results and they complete each other in order to observe the differences in the hysteresis curves for different types of load cases.

The F.E.M. model can be used for optimizing the geometry of the component parts in order to achive a special desired hysteresis shape. This optimization process can be done with dampers F.E.M. model presented in this paper, which have been validated with the experimental results.

These hysteresis Bouc-Wen models are useful in computational simulation of buildings equipped with these new dampers for which the F.E.M. software does not have specific damping elements in their finite elements library. An example is our GenEcAm software [4]. A great advantage of using SERB devices is the cost of the damping system which is five times smaller than the same damping system which use Taylor devices.

This work was partially supported by the grant number $44 \mathrm{C} / 27.01 .2014$, awarded in the internal grant competition of the University of Craiova.

\section{References}

[1] A. Ionescu, M. Calbureanu, M. Negru - Static and Dynamic Simulation in the Seismic Behavior of a Building Structure using ANSYS Program, International Journal of Mechanics, NAUN Journal 2013, vol. 7, pag. 210-217, ISSN: 1998-4448.

[2] A. Ionescu, M. Negru, C. Burada, Influence of non-linear properties of fluid viscoelastic properties on seismic damping properties of a ten stories building using ANSYS program, Journal Advanced Concepts in Mechanical Engineering, ACME 2014, Trans Tech Publication, Elvetia.

[3] A. Ionescu, M. Negru, C. Burada, Optimal configuration of fluid viscoelastic seismic dampers on a ten stories building using Finite Elements Method, Journal - Advanced Concepts in Mechanical Engineering, ACME 2014, Trans Tech Publication, Elvetia.

[4] A. Ionescu, C. Burada, M. Calbureanu, M. Negru, Computational model of buildings equipped with different devices for seismic damping, $3^{\text {rd }}$ International Conference on Energy and Environment Technologies and Equipment, WSEAS EEETE'14, Brasov, Romania, june 26-28, 2014.

[5] A. Ionescu, C. Burada, M. Calbureanu, M. Negru, F.E.M. studies concerning new devices for seismic damping of buildings subjected to romanian Vrancea earthquakes, $3^{\text {rd }}$ International Conference WSEAS, ABIFA'14, Brasov, Romania, june 26-28, 2014. 